\title{
Rapid and controlled electrochemical synthesis of crystalline niobium oxide microcones
}

ARTICLE in MRS COMMUNICATIONS · JUNE 2015

Impact Factor: 1.55 · DOI: 10.1557/mrc.2015.43

CITATION

1

5 AUTHORS, INCLUDING:

Nageh K. Allam

Massachusetts Institute of Technology

94 PUBLICATIONS 1,591 CITATIONS

SEE PROFILE
READS

46 


\title{
Rapid and controlled electrochemical synthesis of crystalline niobium oxide microcones
}

\author{
Basamat S. Shaheen, Energy Materials Laboratory, School of Sciences and Engineering, The American University in Cairo, New Cairo 11835, Egypt; \\ Materials Science, California Institute of Technology, Pasadena, California 91125 \\ Timothy C. Davenport, Materials Science, California Institute of Technology, Pasadena, California 91125; Present address: Department of Materials \\ Science and Engineering, Northwestern University, 2200 Campus Dr., Evanston, Illinois 60208 \\ Hanadi G. Salem, Energy Materials Laboratory, School of Sciences and Engineering, The American University in Cairo, New Cairo 11835, Egypt \\ Sossina M. Haile, Materials Science, California Institute of Technology, Pasadena, California 91125; Present address: Department of Materials Science \\ and Engineering, Northwestern University, 2200 Campus Dr., Evanston, Illinois 60208 \\ Nageh K. Allam, Energy Materials Laboratory, School of Sciences and Engineering, The American University in Cairo, New Cairo 11835, Egypt; Materials \\ Science, California Institute of Technology, Pasadena, California 91125 \\ Address all correspondence to N. K. Allam at nageh.allam@aucegyt.edu
}

(Received 8 May 2014; accepted 10 June 2015)

\begin{abstract}
We demonstrate the fabrication by anodization of niobium oxide microcones, several microns long, from aqueous solutions of $1 \mathrm{wt} \%$ hydrogen fluoride (HF) with varied sodium fluoride (NaF) concentration $(0-1 \mathrm{M})$. Raman spectroscopy and $x$-ray diffractometer analysis revealed the as-grown microcones to be crystalline $\mathrm{Nb}_{2} \mathrm{O}_{5-x}$ with preferred $\left(\begin{array}{ll}1 & 0\end{array}\right)$ and $\left(\begin{array}{lll}0 & 1\end{array}\right)$ orientations. The overall $\mathrm{Nb}_{2} \mathrm{O}_{5-x}$ formation rate increased with the increasing $\mathrm{NaF}$ concentration, and structures as tall as $20 \mu \mathrm{m}$ were achieved in just 20 min of anodization at $1 \mathrm{M} \mathrm{NaF}$. Rapid formation of niobia microcones was even observed in the absence of $\mathrm{HF}$ at this NaF concentration. Photocatalytic activity for water oxidation was highest for microcones grown under the highest NaF concentration.
\end{abstract}

\section{Introduction}

Niobium oxides offer rich chemistry, existing in many chemical forms with variable stoichiometries, leading to a large variety of structures, properties, and applications. ${ }^{[1-3]}$ Anodization is an attractive method for fabricating oxides, including those of niobium, because of the possibility of creating self-organized structures with a high degree of order. While far less studied than aluminum, anodization of niobium has been reported to result in structures ranging from random porous films ${ }^{[4]}$ and sunflower formations ${ }^{[5]}$ to granular forms ${ }^{[6]}$ and membranes with smooth, linear pores ${ }^{[7]}$ or with rough, vein-like pores. ${ }^{[8]}$ A particularly intriguing morphology is that of microcones, which appears to be unique to anodized niobium. The niobia microcone morphology was first reported by Karlinsey, resulting from anodization in an aqueous electrolyte of $\mathrm{HF}^{[9]}$ or $\mathrm{HF}$ plus $\mathrm{NaF}^{[10]}$ Habazaki and co-workers have subsequently shown that microcones can also be generated from anodization in a hot glycerol electrolyte containing both $\mathrm{K}_{2} \mathrm{HPO}_{4}$ and $\mathrm{K}_{3} \mathrm{PO}_{4}{ }^{[11,12]}$ Where crystallinity has been examined (by diffraction), it has been found that microcone niobium oxide is crystalline as grown, in contrast to the majority of other oxides formed by anodization, which are typically amorphous. Though the microstructural characteristics have not yet been studied in detail, microconical niobium oxide has the appearance of rough nanowires or needles that extend from the underlying substrate and clump into tent-like hillocks. ${ }^{[10,13]}$ The high surface area, morphological regularity, and as-grown crystallinity of this structure render it attractive for a variety of applications. In particular, it has been considered for biomedical applications, displaying favorable nucleation activity for biological minerals, ${ }^{[14]}$ as a coating to create surfaces of tuned wettability, ${ }^{[11,12]}$ and as a photoanode in dye-sensitized solar cells. ${ }^{[13]}$ These features may also be relevant to electrochromic response, which has emerged as a new area of application for anodized niobia. ${ }^{[15]}$

The relative scarcity of information regarding the crystallization behavior of microcone anodized niobia motivates a greater examination of the process. In particular, we explore here the role of $\mathrm{NaF}$ concentration in aqueous electrolytes containing both $\mathrm{NaF}$ and $\mathrm{HF}$ on morphology and crystallinity, as a parameter that is easily modified but for which clear trends are not yet known. The influence of post-growth annealing is also explored.

\section{Experimental methods}

Niobium foil (Sigma Aldrich 99.8\%, $0.25 \mathrm{~mm}$ in thickness) was cut into pieces $\left(2 \times 1 \mathrm{~cm}^{2}\right)$, and then ultrasonically cleaned in acetone, ethanol, and deionized water, respectively. A two-electrode electrochemical cell was used for anodization in which the $\mathrm{Nb}$ metal foil was the positive electrode and a 
platinum foil was the negative electrode. Both electrodes were connected to a DC voltage power supply and immersed in 50 $\mathrm{ml}$ of electrolyte solutions containing different concentrations of NaF (Sigma Aldrich, 99.99\%) and HF (Sigma Aldrich, $48 \%$ assay in $\mathrm{H}_{2} \mathrm{O}$ ) in deionized water. In a series of five solutions, the $\mathrm{HF}$ concentration was fixed at $1 \mathrm{wt} \%$ and the $\mathrm{NaF}$ molarity varied from 0 to $1 \mathrm{M}$. An additional solution with 1 $\mathrm{M} \mathrm{NaF}$ and no HF was also examined. All samples were anodized at $40 \mathrm{~V}$ for 20 min under continuous stirring. The temperature of the solution, which was neither heated nor cooled, was monitored by insertion of a thermometer. The oxide formed under $1 \mathrm{M} \mathrm{NaF}$ (and $1 \mathrm{wt} \% \mathrm{HF}$ ) was further evaluated after annealing under stagnant air at $440{ }^{\circ} \mathrm{C}$ for $20 \mathrm{~min}$.

The surface morphology of the resulting structures, a layer of anodized material supported on remaining metal, was studied using a field-emission scanning electron microscope (FESEM-Zeiss SEM Ultra60). The structures were further investigated using an $\mathrm{x}$-ray diffractometer (XRD; PANalytical X'Pert PRO diffractometer with $\mathrm{Cu} \mathrm{K}_{\alpha}$ radiation). Raman measurements were performed on a Raman microscope (ProRaman-L Analyzer) with an excitation laser wavelength of $532 \mathrm{~nm}$. Preliminary measurements of steady-state photocurrent density were carried out in $1 \mathrm{M} \mathrm{Na}_{2} \mathrm{SO}_{4}$ under AM 1.5 illumination at an applied voltage of $0.5 \mathrm{~V}_{\mathrm{Ag} / \mathrm{AgCl}}$.

\section{Results and discussions}

Figures 1(a)-1(e) show FESEM images of as-anodized niobium oxide microcones fabricated in aqueous electrolytes containing $\mathrm{HF}(1 \mathrm{wt} \%)$ and different concentrations of $\mathrm{NaF}(0-1 \mathrm{M})$; the length of these microcones is summarized in Fig. 2. In the absence of $\mathrm{NaF}$ or at low $\mathrm{NaF}$ concentrations $(\leq 0.1 \mathrm{M})$, despite the presence of HF, very few microcones form. The oxide adopts a random morphology, Figs. 1(a) and 1(b), and the thickness of this layer is $2-3 \mu \mathrm{m}$. In contrast, solutions with $\mathrm{NaF}$ concentration from 0.2 to $1 \mathrm{M}$ show well-developed microcones, with heights between 17 and $20 \mu \mathrm{m}$. Surprisingly, even in the absence of HF, the $1 \mathrm{M} \mathrm{NaF}$ electrolyte produces a uniform surface of well-developed microcones [Fig. 1(f)]. This behavior, which is the first report of microcone formation from a slightly basic solution ( $1 \mathrm{M} \mathrm{NaF}$ in water results in a $\mathrm{pH}$ of 8.6), is advantageous since it avoids the extreme safety precautions required when handling HF. Annealing the as-grown structures produces few morphological changes, as evident from a comparison of Figs. 1(e) and 1(g).

The XRD patterns obtained from the niobium oxide structures shown in Fig. 1 are presented in Fig. 3. In the absence of $\mathrm{NaF}$ (pattern a), only $\mathrm{Nb}$ metal peaks are detected, indicating the oxide layer formed from the electrolyte containing only HF [Fig. 1(a)] is either not crystalline or too small in quantity to detect. Upon introduction of $\mathrm{NaF}$, diffraction peaks appear at approximately $28^{\circ}$ and $49.9^{\circ} 2 \theta$, with intensities that generally increase with increasing $\mathrm{NaF}$ concentration (patterns $\mathrm{b}-\mathrm{e}$ ). These are identified as the $\left(\begin{array}{lll}2 & 0 & 0\end{array}\right)$ and $\left(\begin{array}{lll}0 & 16 & 0\end{array}\right)$ peaks, respectively, of orthorhombic $\mathrm{T}-\mathrm{Nb}_{2} \mathrm{O}_{5} \cdot{ }^{[16-18]}$ In addition, a lowangle shoulder on the $\left(\begin{array}{lll}2 & 0 & 0\end{array}\right)$ peak, distinct from the $\left(\begin{array}{lll}1 & 8 & 0\end{array}\right)$ peak, is also evident. The pattern from the material obtained by anodization in only $\mathrm{NaF}$ (pattern $\mathrm{f}$ ) is similar to the others, corroborating the conclusion from the microstructural investigations that $\mathrm{HF}$ is not essential to the formation of crystalline microcones. On annealing (pattern $\mathrm{g}$ ), all residual $\mathrm{Nb}$ metal peaks disappear. Moreover, the low-angle shoulder on the (2 $00)$ peak, evident in the patterns of the as-prepared samples, also disappears, a factor discussed below.

Beyond the clear increase of oxide phase fraction with $\mathrm{NaF}$ concentration, a striking feature of the diffraction data is the high degree of preferred orientation. In comparison with the expected pattern for randomly oriented $\mathrm{T}-\mathrm{Nb}_{2} \mathrm{O}_{5}$, the diffraction patterns recorded here display extremely enhanced intensity of the $\left(\begin{array}{lll}2 & 0 & 0\end{array}\right)$ and $\left(\begin{array}{lll}0 & 16 & 0\end{array}\right)$ peaks. For example, in the absence of preferred orientation, the ( $\left.\begin{array}{lll}1 & 8 & 0\end{array}\right)$ peak will have the highest intensity, followed closely by the $\left(\begin{array}{lll}0 & 0 & 1\end{array}\right)$ peak, and the $\left(\begin{array}{lll}0 & 16\end{array}\right.$ $0)$ will have an intensity approximately a tenth of that. The result obtained here is interpreted as follows. $\mathrm{T}-\mathrm{Nb}_{2} \mathrm{O}_{5}$ has a layered structure with edge-shared $\mathrm{NbO}_{6}$ and $\mathrm{NbO}_{7}$ polyhedra forming a layer in the $(a-b)$ plane. These layers are linked by corner sharing of the polyhedra along the $z$-direction. ${ }^{[18]}$ Enhanced intensity of the only significant $\left(\begin{array}{lll}h & 0 & 0\end{array}\right)$ and $\left(\begin{array}{ll}0 & k\end{array}\right)$ peaks in the patterns of the anodized niobia suggests that the layers stand essentially on edge, with the $c$-axis of the structure lying parallel to the underlying $\mathrm{Nb}$ substrate. With increasing $\mathrm{NaF}$ concentration the preference for the $(0 k 0)$ orientation relative to the $(h 00)$ orientation increases, as evident from a slight increase in the relative intensity of the $(0160)$ peak. The occurrence of the $\left(\begin{array}{lll}0 & 0 & 1\end{array}\right)$ peak in pattern $\mathrm{c}$ indicates that the precise orientation adopted may depend on other, unidentified experimental factors.

The low-angle shoulder on the (2 00$)$ peaks is interpreted to reflect the existence of a slightly reduced $\mathrm{T}-\mathrm{Nb}_{2} \mathrm{O}_{5-x}$ minority phase. A shift of the (2 00$)$ peak toward a smaller $2 \Theta$ value is consistent with lattice expansion reported for $\mathrm{Nb}_{2} \mathrm{O}_{5-x}{ }^{[19]}$ Annealing [Fig. 3(g)] removes the shoulder and any evidence of the reduced phase. While not a central aspect of this study, it can be concluded that the as-anodized samples consist of a mixture of partially reduced and fully oxidized phases, and the heat treatment results in full oxidation. From the peak widths (in combination with the Scherer equation ${ }^{[20]}$ ), the crystallite sizes are estimated to be $\sim 15 \mathrm{~nm}$ in the fully oxidized phase and slightly smaller, $\sim 14 \mathrm{~nm}$, in the partially reduced phase. Moreover, the relative intensity of the shoulder indicates that the reduced phase accounts for $1 / 3$ to $2 / 5$ of the oxide content in the as-anodized films. Annealing has no detectable effect on the crystallite size in the fully oxidized $\mathrm{T}-\mathrm{Nb}_{2} \mathrm{O}_{5}$. While the preferred orientation, phase coexistence and particle size induced peak-broadening introduce challenges for detailed evaluation of the diffraction data, Rietveld analysis (PANalytical X'Pert Plus commercial software package) was carried out to estimate the phase fractions of niobia (including both the fully oxidized and slightly reduced forms) and $\mathrm{Nb}$ phases sampled by the X-radiation. The results, Fig. 4, show the oxide phase fraction to increase monotonically with $\mathrm{NaF}$ 

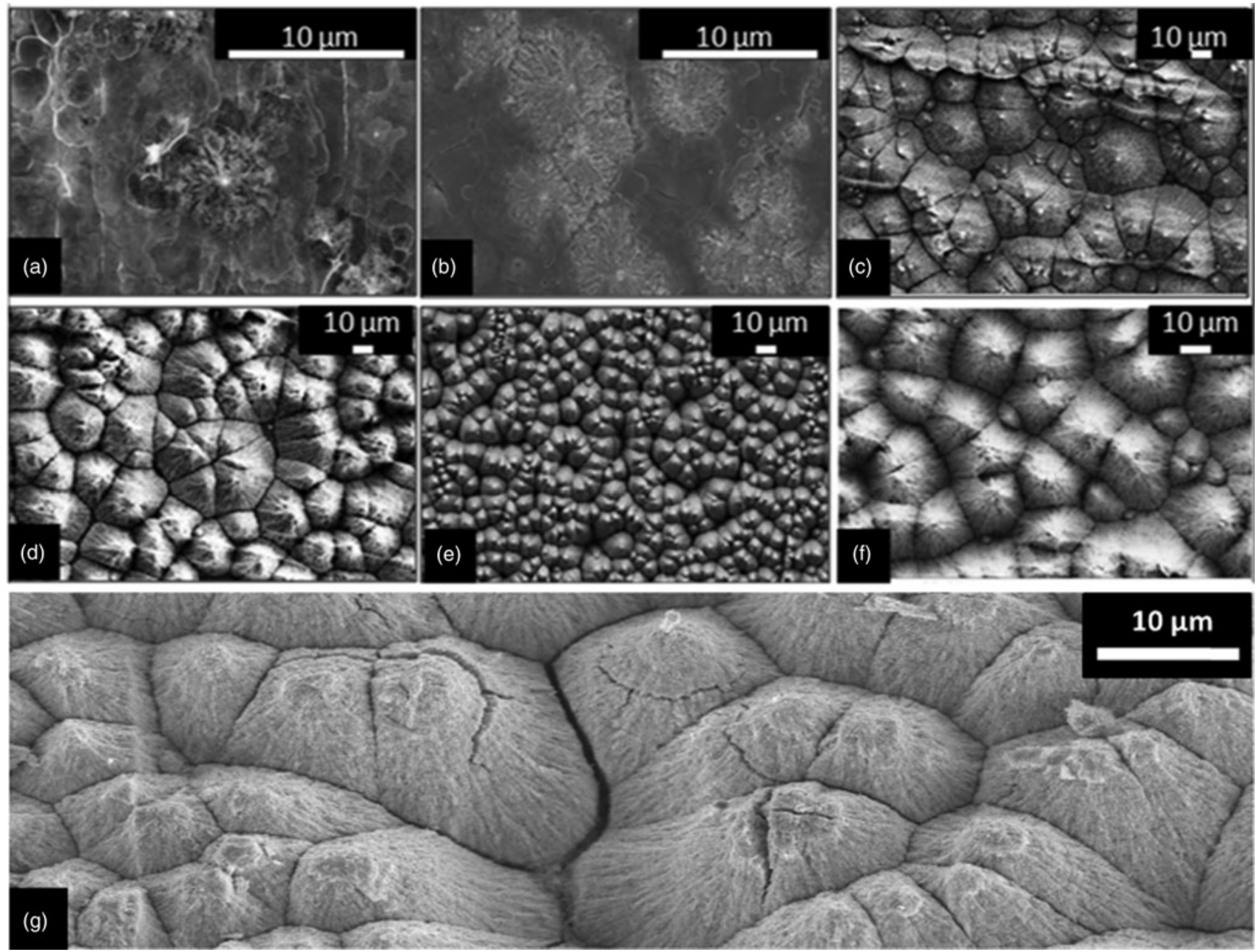

Figure 1. FESEM of the niobium oxide microcones obtained via anodization at $40 \mathrm{~V}$ for 20 min in aqueous electrolytes containing (a-e) $1 \mathrm{wt} \% \mathrm{HF}$ and (a) 0 , (b) 0.1 , (c) 0.2 , (d) 0.5 , (e) $1 \mathrm{M} \mathrm{NaF}$; (f) $1 \mathrm{M} \mathrm{NaF}+0 \mathrm{wt} \% \mathrm{HF}$, and (g) $1 \mathrm{M} \mathrm{NaF}+1 \mathrm{wt} \% \mathrm{HF}$ after being annealed in air at $440{ }^{\circ} \mathrm{C}$ for $20 \mathrm{~min}$.

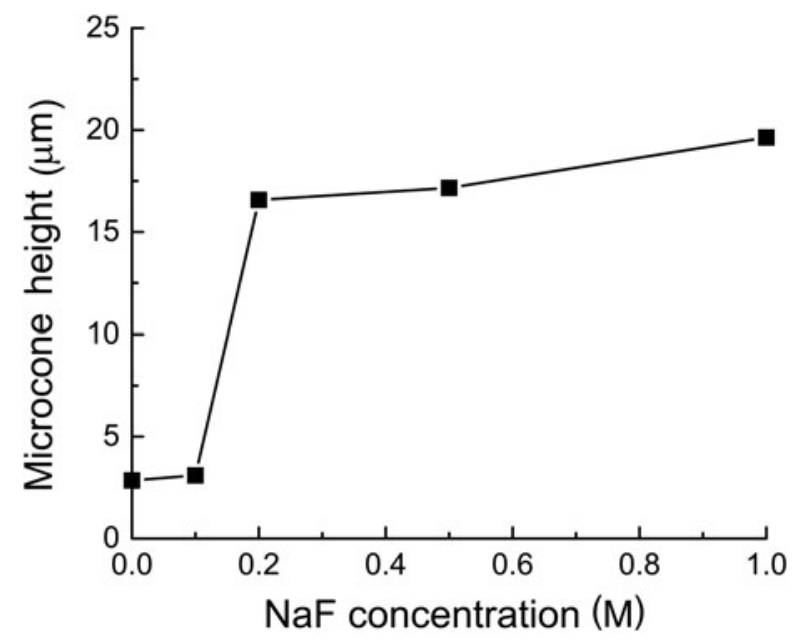

Figure 2. Variation of the height of the microcones as a function of $\mathrm{NaF}$ concentration in the aqueous electrolyte (1 wt \% HF, $40 \mathrm{~V}, 20 \mathrm{~min}$ ). concentration in the electrolyte (as immediately evident from the raw diffraction patterns). For electrolyte solutions with $0.5 \mathrm{M} \mathrm{NaF}$ or greater (in $1 \mathrm{wt} \% \mathrm{HF}$ ), the underlying $\mathrm{Nb}$ foil is barely detectable.

The Raman spectra for two samples, specifically, those anodized using $1 \mathrm{M} \mathrm{NaF}$ and $1 \mathrm{wt} \% \mathrm{HF}$, without and with a postanodization annealing step, are presented in Fig. 5. The spectra for other samples (none of which were annealed) were similar to that of the as-anodized sample and are omitted for clarity. Both spectra shown, with peaks at $\sim 235, \sim 315$, and $\sim 700 \mathrm{~cm}^{-1}$, are in excellent agreement with those reported in the literature for $\mathrm{T}_{-} \mathrm{Nb}_{2} \mathrm{O}_{5} \cdot{ }^{[8,21,22]}$ The two low wave-number peaks have been loosely ascribed to $\mathrm{Nb}-\mathrm{O}-\mathrm{Nb}$ bending modes and that at $\sim 700 \mathrm{~cm}^{-1}$ to $\mathrm{Nb}-\mathrm{O}$ stretching modes. As shown in Fig. 5, the features of the bending mode peaks do not change on annealing, whereas the stretching mode peak sharpens and shifts to higher wave number, from 690 to $708 \mathrm{~cm}^{-1}$. These are interpreted to reflect, respectively, an increase in crystallinity (without change in crystallite size) and the increase in 


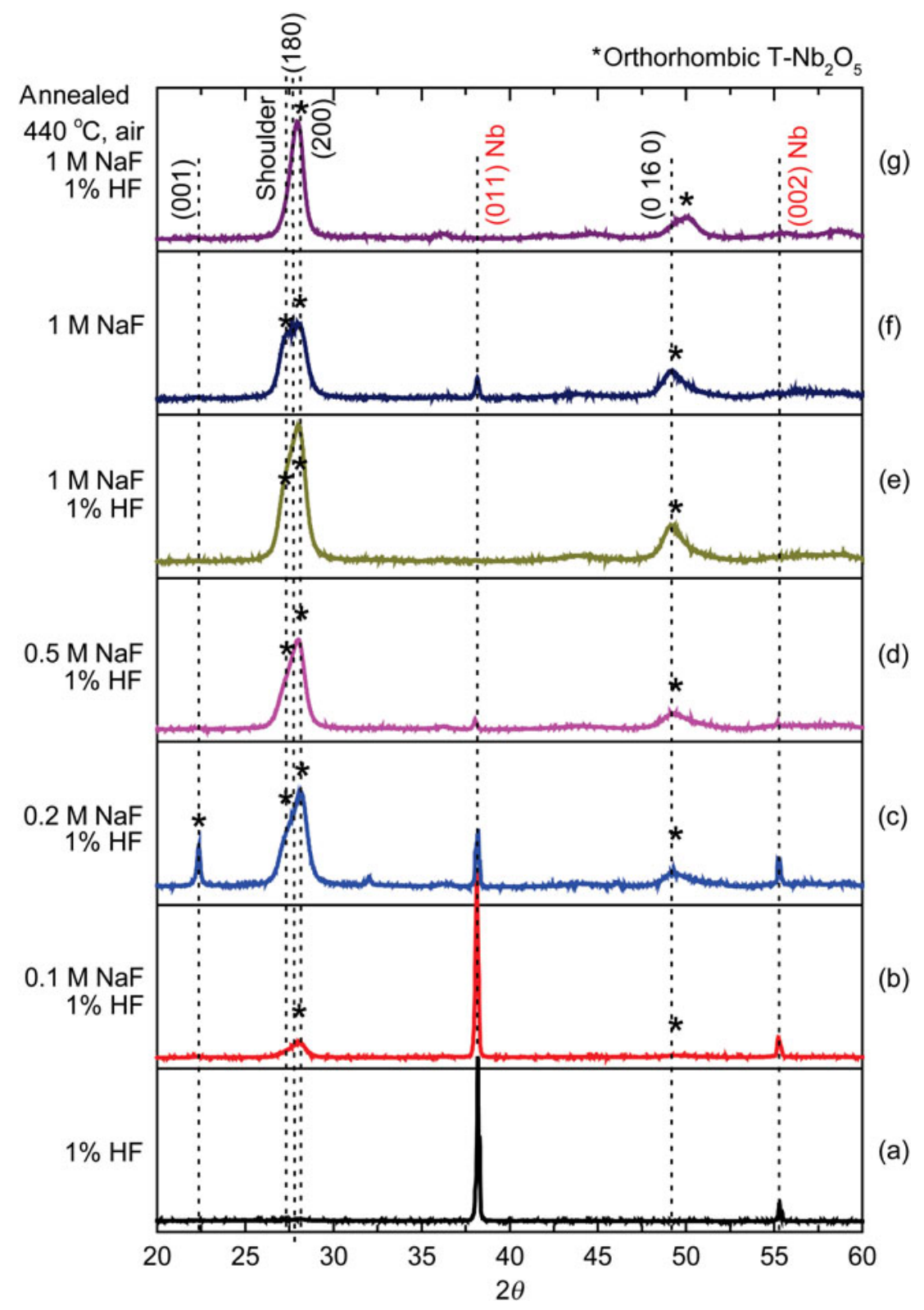

Figure 3. XRD patterns of the niobium oxide microcones obtained via anodization at $40 \mathrm{~V}$ for $20 \mathrm{~min}$ in aqueous electrolytes containing (a-e) $1 \mathrm{wt} \% \mathrm{HF}$ and (a) 0 , (b) 0.1 , (c) 0.2 , (d) 0.5 , (e) $1 \mathrm{M} \mathrm{NaF}$, (f) $1 \mathrm{M} \mathrm{NaF}+0 \mathrm{wt} \% \mathrm{HF}$, and (g) $1 \mathrm{M} \mathrm{NaF}+1 \mathrm{wt} \% \mathrm{HF}$ after being annealed in air at $440^{\circ} \mathrm{C}$ for $20 \mathrm{~min}$.

oxidation state discussed above. A clear correlation between Raman stretching frequencies and $\mathrm{Nb}-\mathrm{O}$ bond distances has been observed in niobium oxide compounds, with increasing frequency correlating to decreasing bond distance, which, in turn, implies, by bond valence arguments, an increase in the oxidation state. $^{[23]}$

Perhaps the most significant findings of this study are that increasing the NaF concentration in the electrolyte solution favors microcone formation, and that under these favorable conditions, well-defined microcone structures are obtained within $20 \mathrm{~min}$. As discussed above, the morphology of the microcones suggests that they are always obtained in the crystalline form, and, thus, factors that favor crystallization may inherently favor microcone formation. The in situ crystallization of anodized niobia has been the subject of much discussion, ${ }^{[24,25]}$ and, indeed, niobium oxide is known to undergo field crystallization much more readily than, for example, tantalum oxide. ${ }^{[26]}$ Although not all crystalline anodized niobia adopts the microcone morphology, where mechanistic investigations have been carried out, microcone ${ }^{[1,27]}$ and related "sunflower"[25] structures have been found to be associated with the crystallization process. A key factor that favors crystallization is increased temperature. Here it was observed that the addition of $\mathrm{NaF}$ to the HF-containing electrolytes results in an increase in 


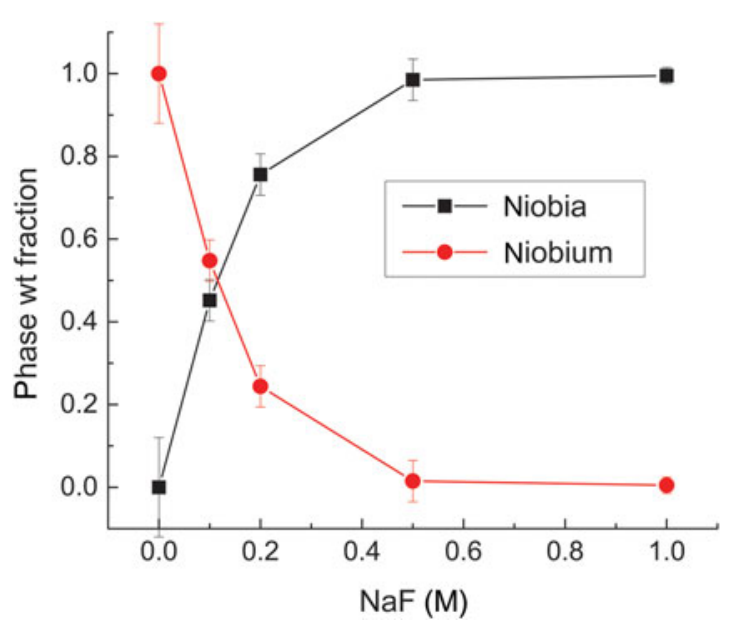

Figure 4. Weight fraction of $\mathrm{Nb}_{2} \mathrm{O}_{5-x}$ and $\mathrm{Nb}$ phases as a function of $\mathrm{NaF}$ concentration in the aqueous electrolyte ( $1 \mathrm{wt} \% \mathrm{HF}, 40 \mathrm{~V}, 20 \mathrm{~min})$.

temperature during anodization (Fig. 6), specifically rising to $\sim 40{ }^{\circ} \mathrm{C}$ after $20 \mathrm{~min}$ for solutions containing $0.5 \mathrm{M} \mathrm{NaF}$. In contrast, for the electrolyte with only HF, the temperature is unchanged even after $50 \mathrm{~min}$. The highly exothermic oxidation reaction (with a standard enthalpy of reaction between $\mathrm{Nb}$ and $\mathrm{H}_{2} \mathrm{O}$ to form $\mathrm{Nb}_{2} \mathrm{O}_{5}$ and $\mathrm{H}_{2}$ of $-2370 \mathrm{~kJ} / \mathrm{mol} \mathrm{Nb} \mathrm{O}_{5}{ }^{[28]}$ ) is presumably the source of the heat, and apparently NaF catalyzes this reaction much more effectively than does HF. Local heating, the dissipation of which will depend on the details of the experimental configuration, may explain some slight discrepancies between the present work and earlier literature results. For example, Karlinsey suggested that introducing $\mathrm{NaF}$

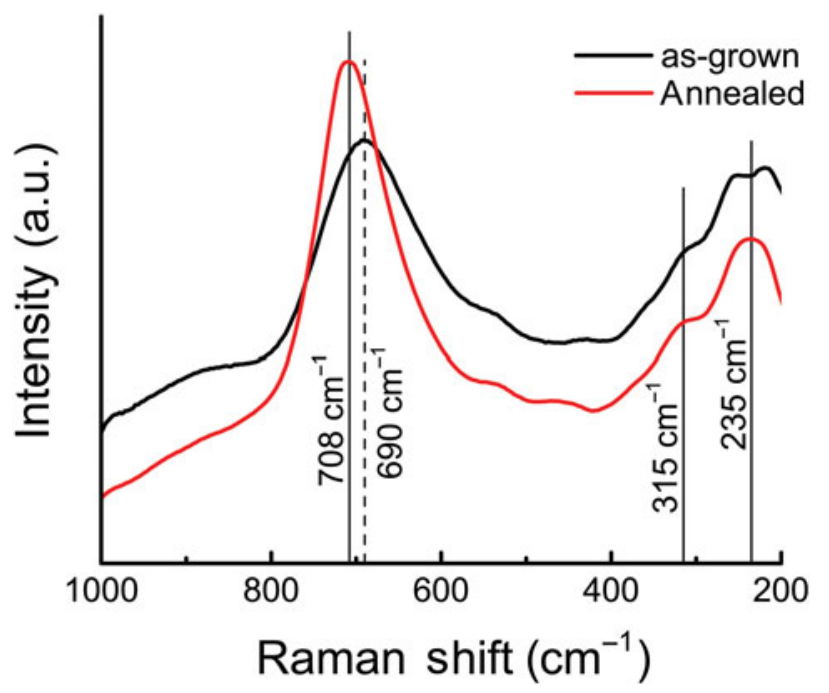

Figure 5. Raman spectra of the niobium oxide microcones obtained via anodization at $40 \mathrm{~V}$ for $20 \mathrm{~min}$ in an aqueous electrolyte containing $1 \mathrm{wt} \% \mathrm{HF}$ and $1 \mathrm{M} \mathrm{NaF}$, as-grown and after annealing in air at $440^{\circ} \mathrm{C}$ for $20 \mathrm{~min}$ (as labeled).

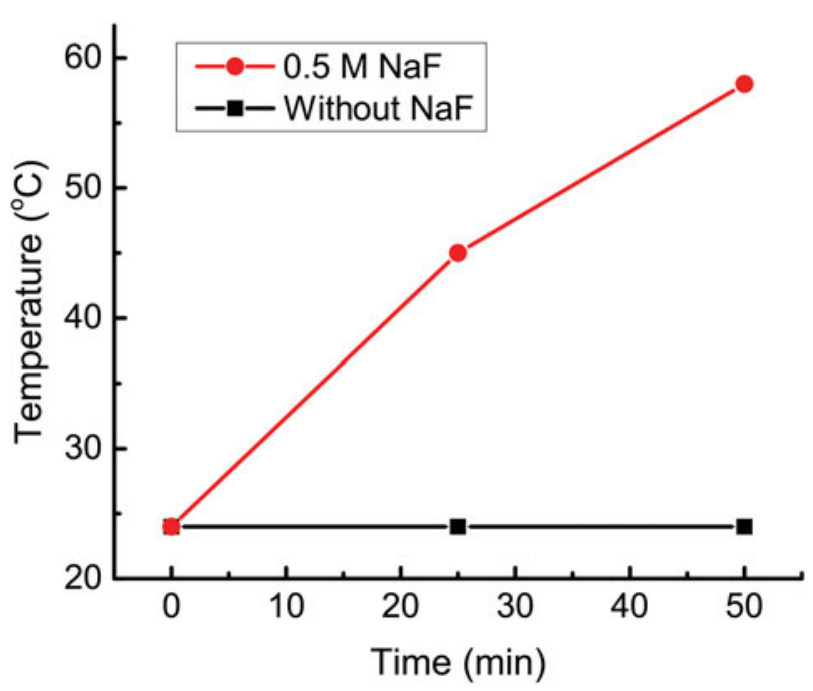

Figure 6. Variation in the electrolyte temperature during the anodization of niobium at $40 \mathrm{~V}$ for $50 \mathrm{~min}$ in $1 \mathrm{wt} \% \mathrm{HF}$ without and with $0.5 \mathrm{M} \mathrm{NaF}$ as indicated.

(at an unspecified concentration) in an electrolyte of $2.5 \mathrm{wt} \%$ HF retards microcone growth, ${ }^{[10]}$ and Jeong and Jung have reported that at least $30 \mathrm{~min}$ is required to achieve visible microcone growth for anodization in a solution of $1 \mathrm{M} \mathrm{NaF}$ and $1 \mathrm{wt}$ $\%$ HF using $40 \mathrm{~V}^{\left[{ }^{[13]}\right.}$ In the present work, well-defined, crystalline microcones, $17 \mu \mathrm{m}$ in height were obtained from a nominally identical solution within $20 \mathrm{~min}$. Agreement with the present study, however, is found in the work of Zhao et al., who reported that in the absence of $\mathrm{NaF}$ almost 60 min of anodization is required in order to nucleate microcones when

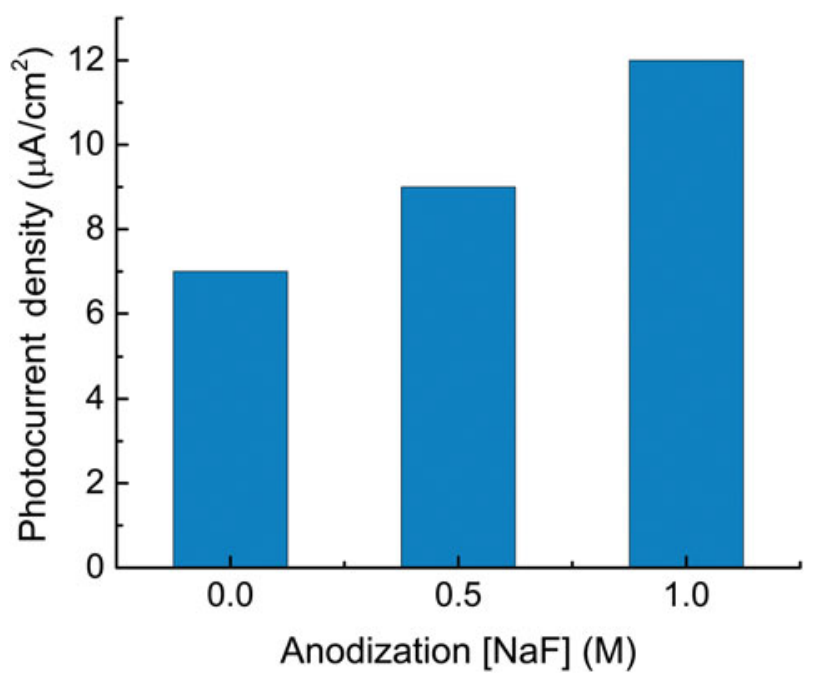

Figure 7. Steady-state photocurrent generated from as-anodized niobia microcones, fabricated in electrolytes containing different $\mathrm{NaF}$ concentrations, tested in $1 \mathrm{M} \mathrm{Na}_{2} \mathrm{SO}_{4}$ under $\mathrm{AM} 1.5$ illumination at an applied voltage of $0.5 \mathrm{~V}_{\mathrm{Ag} / \mathrm{AgCl}}$. 
using a solution of $2 \mathrm{wt} \% \mathrm{HF}$, albeit at a relatively low voltage of $20 \mathrm{~V} .^{[27]}$

The microstructural control afforded by changing the electrolyte composition can be expected to impact the behavior of the microcone niobia in any application of interest. Here we found that the photocatalytic performance of the as-anodized microcones, upon their use as photoanodes to split water, increased with increasing concentration of $\mathrm{NaF}$ used in the anodization (Fig. 7). This behavior may be a result of the concomitant increase in the amount of oxide formed and surface area available for the photocatalysis. The monotonic increase in photocurrent density suggests that $\mathrm{Na}$ or $\mathrm{F}$ impurities, which would otherwise likely result in electron-scattering sites, ${ }^{[29]}$ are not enhanced with increasing NaF concentration. Nevertheless, studies directly aimed at quantifying impurity content will be an important part of future efforts. The highest photocurrent density obtained here, $12 \mu \mathrm{A} / \mathrm{cm}^{2}$, is comparable with or higher than previously reported values for $\mathrm{N}$-doped $\mathrm{Nb}_{2} \mathrm{O}_{5}$ measured under similar conditions: $13 \mu \mathrm{A} / \mathrm{cm}^{2}$ in the case of planar films (at $0.5 \mathrm{~V}$ versus $\mathrm{Ag} / \mathrm{AgCl}$ ) ${ }^{[30]}$ and $7 \mu \mathrm{A} / \mathrm{cm}^{2}$ for material prepared in the ordered mesoporous form (at $1.2 \mathrm{~V}$ versus $\mathrm{Ag} / \mathrm{AgCl}) .{ }^{[31]}$ Though not yet competitive with materials such as $\mathrm{BiVO}_{4}$ and $\mathrm{WO}_{3}$, for which current densities of order of $0.5 \mathrm{~mA} / \mathrm{cm}^{2}$ have been reported ${ }^{[32]}$ this study reveals the tunability of properties afforded by control of the microcone growth conditions.

\section{Conclusions}

In summary, we demonstrate the rapid growth of crystalline niobium oxide microcones several microns in length via anodization of niobium metal. In contrast to earlier suggestions in the literature, introduction of $\mathrm{NaF}$ into the aqueous $\mathrm{HF}$ electrolyte solution enhances crystallization and microcone formation. For solutions containing $\geq 0.2 \mathrm{M} \mathrm{NaF}$ well-developed microcones are distributed homogenously over the entire surface. Even in the absence of HF, microcones can be synthesized in $1 \mathrm{M} \mathrm{NaF}$ aqueous solution, and this unexpected result will be the subject of future studies. The XRD and Raman analysis showed that the as-anodized microcones are crystalline and slightly reduced, and that a mild heat treatment in air results in full oxidation. We observed an increase in the electrolyte temperature during anodization in solutions containing $\mathrm{NaF}$, in contrast to those containing only HF, a factor which is presumed to contribute to effective microcone formation in the presence of NaF. A preliminary investigation of the photocatalytic activity of the as-anodized microcones revealed the determinant effect of $\mathrm{NaF}$ concentration. The structures deliver photocurrent densities comparable with or exceeding those of $\mathrm{N}$-doped counterparts.

\section{Acknowledgments}

B. S. acknowledges financial support from the American University in Cairo via a graduate student research grant.
Additional support was provided by LiOx Power Inc. and by the California Institute of Technology.

\section{References}

1. I.E. Wachs, J.M. Jehng, G. Deo, H. Hu, and N. Arora: Redox properties of niobium oxide catalysts. Catal. Today 28, 199 (1996).

2. R.A. Rani, A.S. Zoolfakar, A.P. O'Mullane, M.W. Austin, and K. KalantarZadeh: Thin films and nanostructures of niobium pentoxide: fundamental properties, synthesis methods and applications. J. Mater. Chem. A 2 , 15683 (2014).

3. I. Nowak and M. Ziolek: Niobium compounds: preparation, characterization, and application in heterogeneous catalysis. Chem. Rev. 99, 3603 (1999).

4. J.E. Yoo, J. Park, G. Cha, and J. Choi: Micro-length anodic porous niobium oxide for lithium-ion thin film battery applications. Thin Solid Films 531, 583 (2013).

5. K. Nagahara, M. Sakairi, H. Takahashi, K. Matsumoto, K. Takayama, and Y. Oda: Mechanism of formation and growth of sunflower-shaped imperfections in anodic oxide films on niobium. Electrochim. Acta 52, 2134 (2007).

6. B. Tzvetkov, M. Bojinov, and A. Girginov: Nanoporous oxide formation by anodic oxidation of $\mathrm{Nb}$ in sulphate-fluoride electrolytes. J. Solid State Electrochem. 13, 1215 (2009).

7. K. Lee, Y. Yang, M. Yang, and P. Schmuki: Formation of highly ordered nanochannel Nb oxide by self-organizing anodization. Chem.: Eur. J. 18, 9521 (2012).

8. J.Z. Ou, R.A. Rani, M.H. Ham, M.R. Field, Y. Zhang, H. Zheng, P. Reece, S. Zhuiykov, S. Sriram, M. Bhaskaran, R.B. Kaner, and K. Kalantar-Zadeh: Elevated temperature anodized $\mathrm{Nb}_{2} \mathrm{O}_{5}$ : a photoanode material with exceptionally large photoconversion efficiencies. ACS Nano 6, 4045 (2012).

9. R.L. Karlinsey: Preparation of self-organized niobium oxide microstructures via potentiostatic anodization. Electrochem. Commun. 7, 1190 (2005).

10. R.L. Karlinsey: Self-assembled $\mathrm{Nb}_{2} \mathrm{O}_{5}$ microcones with tailored crystallinity. J. Mater. Sci. 41, 5017 (2006).

11. S. Yang, H. Habazaki, T. Fujii, Y. Aoki, P. Skeldon, and G.E. Thompson: Control of morphology and surface wettability of anodic niobium oxide microcones formed in hot phosphate-glycerol electrolytes. Electrochim. Acta 56, 7446 (2011).

12. Y. Oikawa, T. Minami, H. Mayama, K. Tsujii, K. Fushimi, Y. Aoki, P. Skeldon, G.E. Thompson, and H. Habazaki: Preparation of selforganized porous anodic niobium oxide microcones and their surface wettability. Acta Mater. 57, 3941 (2009).

13. B.Y. Jeong and E.H. Jung: Micro-mountain and nano-forest pancake structure of $\mathrm{Nb}_{2} \mathrm{O}_{5}$ with surface nanowires for dye-sensitized solar cells. Met. Mater. Int. 19, 617 (2013).

14. R.L. Karlinsey and K. Yi: Self-assembly and bioactive response of a crystalline metal oxide in a simulated blood fluid. J. Mater. Sci.: Mater. Med. 19, 1349 (2008).

15. D.D. Yao, R.A. Rani, A.P. O'Mullane, K. Kalantar-zadeh, and J.Z. Ou: High performance electrochromic devices based on anodized nanoporous $\mathrm{Nb}_{2} \mathrm{O}_{5}$. J. Phys. Chem. C 118, 476 (2014).

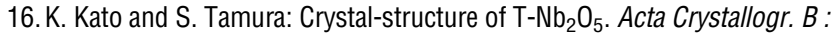
Struct. Sci. 31, 673 (1975).

17. S. Tamura, K. Kato, and M. Goto: Single-crystals of $\mathrm{T}-\mathrm{Nb}_{2} \mathrm{O}_{5}$ obtained by slow cooling method under high-pressures. Z. Anorg. Allg. Chem. 410, 313 (1974).

18. Y. Kobayashi, H. Hata, M. Salama, and T.E. Mallouk: Scrolled sheet precursor route to niobium and tantalum oxide nanotubes. Nano Lett. 7 , 2142 (2007).

19. Y. Murakami, Y. Wada, and A. Morikawa: Catalytic activity of nonstoichiomeric niobium oxide with controlled composition, $\mathrm{NbO}_{2.488-2.500}$, for butene isomerization. Bull. Chem. Soc. Jpn. 61, 2747 (1988).

20. A.L. Patterson: The Scherrer formula for $x$-ray particle size determination. Phys. Rev. 56, 978 (1939).

21.M.R.N. Soares, S. Leite, C. Nico, M. Peres, A.J.S. Fernandes, M.P.F. Graca, M. Matos, R. Monteiro, T. Monteiro, and F.M. Costa: 
Effect of processing method on physical properties of $\mathrm{Nb}_{2} \mathrm{O}_{5}$. J. Eur. Ceram. Soc. 31, 501 (2011).

22. R. Brayner and F. Bozon-Verduraz: Niobium pentoxide prepared by soft chemical routes: morphology, structure, defects and quantum size effect. Phys. Chem. Chem. Phys. 5, 1457 (2003).

23. F.D. Hardcastle and I.E. Wachs: Determination of molybdenum oxygen bond distances and bond orders by Raman-spectroscopy. J. Raman Spectrosc. 21, 683 (1990).

24. J.H. Lim, G. Park, and J. Choi: Synthesis of niobium oxide nanopowders by field-crystallization-assisted anodization. Curr. Appl. Phys. 12, 155 (2012).

25. H. Habazaki, T. Ogasawara, H. Konno, K. Shimizu, S. Nagata, P. Skeldon, and G.E. Thompson: Field crystallization of anodic niobia. Corros. Sci. $\mathbf{4 9}$, 580 (2007).

26. J.F. Jackson and J.C. Hendy: The use of niobium as an anode material in liquid filled electrolytic capacitors. Electrocomp. Sci. Technol. 1, 27 (1974).

27.J.L. Zhao, X.X. Wang, R.Q. Xu, Y.J. Mi, and Y.X. Li: Preparation and growth mechanism of niobium oxide microcones by the anodization method. Electrochem. Solid State Lett. 10, C31 (2007).

28.D.D. Wagman, W.H. Evans, V.B. Parker, R.H. Schumm, I. Halow, S.M. Bailey, K.L. Churney, and R.L. Nuttall: The NBS tables of chemical and thermodynamic properties: selected values for inorganic and $\mathrm{C} 1$ and C2 organic substances in SI units. J. Phys. Chem. Ref. Data 11, Supplement 2, p. 38 and 207 (1982)

29. R.A. Rani, A.S. Zoolfakar, J.Z. Ou, R. Ab Kadir, H. Nili, K. Latham, S. Sriram, M. Bhaskaran, S. Zhuiykov, R.B. Kaner, and K. KalantarZadeh: Reduced impurity-driven defect states in anodized nanoporous $\mathrm{Nb}_{2} \mathrm{O}_{5}$ : the possibility of improving performance of photoanodes. Chem. Commun. 49, 6349 (2013).

30. T. Ruff, R. Hahn, M.S. Killian, H. Asoh, S. Ono, and P. Schmuki: Visible light photo response from $\mathrm{N}$-doped anodic niobium oxide after annealing in ammonia atmosphere. Electrochim. Acta 62, 402 (2012).

31.H. Huang, C. Wang, J. Huang, X.M. Wang, Y.K. Du, and P. Yang: Structure inherited synthesis of $\mathrm{N}$-doped highly ordered mesoporous $\mathrm{Nb}_{2} \mathrm{O}_{5}$ as robust catalysts for improved visible light photoactivity. Nanoscale 6, 7274 (2014).

32. J.Y. Gan, X.H. Lu, and Y.X. Tong: Towards highly efficient photoanodes: boosting sunlight-driven semiconductor nanomaterials for water oxidation. Nanoscale 6, 7142 (2014). 